\title{
Marker based Chemo-profiling of a traditional formulation: Pushyanuga Churna
}

\author{
Sunita Shailajan ${ }^{1 *}$, Yugandhara Patil ${ }^{1}$, Sasikumar Menon ${ }^{2}$ \\ ${ }^{1}$ Herbal Research Laboratory, Ramnarain Ruia College, Mumbai 400 019, India. \\ ${ }^{2}$ Institute for Advanced Training and research in Interdisciplinary Sciences, Mumbai 400 022, India.
}

\begin{tabular}{l} 
ARTICLE INFO \\
\hline Article history: \\
Received on: $27 / 05 / 2017$ \\
Accepted on: $23 / 06 / 2017$ \\
Available online: $30 / 08 / 2017$ \\
\hline Key words: \\
Pushyanuga churna, \\
standardization, Ursolic acid, \\
-sitosterol, Lupeol.
\end{tabular}

$\beta$-sitosterol, Lupeol.

\begin{abstract}
Objectives: Standardization of traditional medicine is a multidimensional approach that ensures the quality and concentration of chemical constituents for their bio-potency. Pushyanuga churna is a traditional ayurvedic formulation prescribed for the treatment of various female reproductive disorders leucorrhoea, menorrhagia etc. As per AFI, the formulation consists of twenty five plants and one mineral. Owing to its therapeutic efficacy, it is prepared and marketed by various manufacturers and vaidyas. Hence, there is an increasing demand but uncertainty about the authenticity of ingredients.

Method: Chemo profiling-assisted characterization of the formulation using HPTLC can help in assuring the quality of the formulation which in turn decides its safety and efficacy. Quantitation of therapeutically reported biomarkers under set optimized chromatographic conditions can be used as a quality control tool.

Results: Fingerprints and quantitation of biomarkers have been used as tools for identification of Pushyanuga Churna. Hence in the present study, an HPTLC method was developed and validated following ICH guidelines for the simultaneous estimation of ursolic acid, $\beta$-sitosterol and lupeol from formulation prepared in-house along with its different manufacturers. Average content of markers was found to be $1.37 \pm 0.108,0.73 \pm 0.025$ and $1.24 \pm 0.136 \mathrm{mg} / \mathrm{g}$ in the in-house formulation and $1.57 \pm 0.027,0.58 \pm 0.024$ and $0.88 \pm 0.089 \mathrm{mg} / \mathrm{g}$ in marketed formulation respectively.
\end{abstract}

\section{INTRODUCTION}

Herbal industry lack rigid quality control profiles. This has become one of the major drawbacks for the globalization of available traditional knowledge. The medicines and practices also include valuable elements and plants sources that are no longer common. Herbal drugs, singularly and in combinations, contain a myriad variety of compounds in complex matrices in which no single active constituent is responsible for the overall efficacy. This creates a challenge in establishing quality control standards for raw materials and the standardization of finished formulation (Singh and Kumar, 2015). According to a report in

\footnotetext{
* Corresponding Author

Dr Sunita Shailajan, Associate Professor (Botany),

Ramnarain Ruia College, Matunga, Mumbai-400019, India.

Email: sunitashailajan @ gmail.com,Tel 02224154390.
}

the $44^{\text {th }}$ World Health Assembly, emphasized the great importance of medicinal plants to the health of individuals and communities (Rastogi, 2012; Khare and Katiyar, 2012). Various Ayurvedic herbal and herbo-mineral preparations are used for the treatment of chronic and degenerative diseases with negligible side-effects (WHO, 2001). Standardization assures the quality, efficacy, performance and safety as these formulations are easily available in the market under the claims of being a cosmeceutical and nutraceutical product by various manufacturers (Kamboj, 2012). Chromatographic fingerprints play a vital role in the complex herbal medicines (Gong et al., 2005). Since they represent the chemical integrities of the herbal medicines and its products and therefore used for authentication and identification of herbal plants (Liang et al., 2004). Strict adherence to standardization procedures needs to be established for every plant medicine in the market because the scope for variation in different batches is enormous (jyotshna and Singh, 2013). 
Different ayurvedic formulations like Pathadi Kwatha, Ashokaristha etc are reported to treat various female reproductive disorders. Pushyanuga churna (AFI-I, 2003; API-II, 2008) is one such popular, non-hormonal Ayurvedic formulation described in Ayurvedic text Charaka Samhita. Pushyanuga churna consists of twenty five medicinal plants and one mineral drug i.e. gairika (red ochre). Ayurvedic Formulary of India prescribes Pushyanuga churna for disorders like menorrhagia, leucorrhoea, disorders of female genital tract etc. In India, due to the popularity of Ayurvedic medicine and marked therapeutic effect of Pushyanuga Churna in the female reproductive disorders, the formulation is being prepared and marketed by various manufacturers like Dabur, Baidyanath, Arkashala, Dhootpapeshwar and by local Vaidyas etc.

The word 'Pushya' refers to Pushya nakshatra as according to Acharya Charak, collection of constituent drugs and the preparation of Pushyanuga churna should be done during pushya nakshatra. Sharan et al., suggests that medicinal plants get special properties during this nakshatra which can be utilized for healthy conception and treatment, and would lead to the production of a formulation with maximum potency (Sharan, 2016). Though the reports of experimental use of Pushyanuga churna and its ingredients in treating various gynaecological disorders are available (Devi, 2007; Khot et al., 2013), basic scientific standardization of the formulation is lacking. There is also a paucity of scientific data to support the assessment of quality, safety and pharmagnostic evaluation of Pushyanuga churna. Therefore, in the current research work, an attempt has been made to standardize Pushyanuga churna, in terms of its phytochemical, physicochemical parameters, chromatographic fingerprinting analysis and biomarker estimation. The current research data can be used in the standardization of the formulation. Similarly the chromatographic evaluation of the formulation can be used as a simple and rapid identification method for the prevention of adulteration and loss of quality. The data generated hence forms a report which can be used by the manufacturing units of Pushyanuga Churna.

\section{MATERIALS AND METHOD}

\section{Chemicals and reagents}

Chemicals of HPTLC grade were purchased from Merck Specialities Pvt. Ltd, Mumbai. The reference standards ursolic acid (98.5\% purity), $\beta$-sitosterol (98.0\% purity) and lupeol (97.0\% purity) were procured from Sigma Aldrich Chemical Company, Steinheim, Germany. The derivatizing agent i.e. $10 \%$ methanolic sulphuric acid was prepared according to the procedure described by Reich and Schibli (Reich and Schibli, 2006).

\section{The following is the list of ingredients present in Pushyanuga Churna as per AFI}

All the plant materials were collected manually from their respective habitats. Plant materials were authenticated from Agharkar Research Institute, Pune and by Dr. Sunita Shailajan, (HOD, Department of Botany) at, Ramnarain Ruia College,
Mumbai. Samples were carefully segregated, cleaned, shade dried for a week and oven dried at $37{ }^{\circ} \mathrm{C}$ to constant weight. Further, the samples were powdered using an electric mixer grinder, sieved (BSS 85) and stored in airtight pearlpet bottles at room temperature.

\begin{tabular}{|c|c|c|c|}
\hline Sr. & Name of plants & Parts used & Collection site \\
\hline 1 & $\begin{array}{l}\text { Cissampelos } \\
\text { pareira }\end{array}$ & Roots & Tungareshwar, Maharashtra \\
\hline 2 & Syzygium cumini & Endosperm & Boisar, Maharashtra \\
\hline 3 & Mangifera indica & Endosperm & Boisar, Maharashtra \\
\hline 4 & Bergenia ligulata & Rhizome & Vishnuprayag, Uttarakhand \\
\hline 5 & Berberis aristata & Root/stem & Pipalkoti, Uttarakhand \\
\hline 6 & $\begin{array}{l}\text { Hibiscus } \\
\text { sabdariffa }\end{array}$ & Root & Mosam, Maharashtra \\
\hline 7 & $\begin{array}{l}\text { Salmalia } \\
\text { malabarica }\end{array}$ & Exudate & Khopoli, Maharashtra \\
\hline 8 & Mimosa pudica & Whole plant & Yeoor, Maharashtra \\
\hline 9 & $\begin{array}{l}\text { Nelumbo } \\
\text { nucifera }\end{array}$ & Androecium & Kale, Maharashtra \\
\hline 10 & Crocus sativus & Style/stigma & $\begin{array}{l}\text { Marketed, Badrinath, } \\
\text { Uttarakhand }\end{array}$ \\
\hline 11 & $\begin{array}{l}\text { Aconitum } \\
\text { heterophylum }\end{array}$ & Root & $\begin{array}{l}\text { Marketed, Pydhonie, } \\
\text { Maharashtra }\end{array}$ \\
\hline 12 & $\begin{array}{l}\text { Cyperus } \\
\text { rotundus }\end{array}$ & Root tuber & Chena Creek, Maharashtra \\
\hline 13 & Aegle marmelos & Stem bark & Junagarh, Gujarat \\
\hline 14 & $\begin{array}{l}\text { Symplocos } \\
\text { racemosa }\end{array}$ & Stem bark & $\begin{array}{l}\text { Mahabaleshwar, } \\
\text { Maharashtra }\end{array}$ \\
\hline 15 & Red ochre & - & $\begin{array}{l}\text { Marketed, Pydhonie, } \\
\text { Maharashtra }\end{array}$ \\
\hline 16 & Myrica esculenta & Stem bark & Khirsu Village, Uttarakhand \\
\hline 17 & Piper nigrum & Fruit & $\begin{array}{l}\text { Marketed, Pydhonie, } \\
\text { Maharashtra }\end{array}$ \\
\hline 18 & $\begin{array}{l}\text { Zingiber } \\
\text { officinale }\end{array}$ & Rhizome & $\begin{array}{l}\text { Marketed, Pydhonie, } \\
\text { Maharashtra }\end{array}$ \\
\hline 19 & Vitis vinifera & Dried fruit & $\begin{array}{l}\text { Marketed, Pydhonie, } \\
\text { Maharashtra }\end{array}$ \\
\hline 20 & $\begin{array}{l}\text { Pterocarpus } \\
\text { santalinus }\end{array}$ & Heart wood & $\begin{array}{l}\text { Marketed, Pydhonie, } \\
\text { Maharashtra }\end{array}$ \\
\hline 21 & Ailanthus excelsa & Stem bark & Pune, Maharashtra \\
\hline 22 & $\begin{array}{l}\text { Holarrhena } \\
\text { antidysenterica }\end{array}$ & Stem bark & Yeoor Hills, Maharashtra \\
\hline 23 & $\begin{array}{l}\text { Hemidesmus } \\
\text { indicus }\end{array}$ & Root & Yeoor Hills, Maharashtra \\
\hline 24 & $\begin{array}{l}\text { Woodfordia } \\
\text { fruticosa }\end{array}$ & Flower & Ambi Valley, Maharashtra \\
\hline 25 & $\begin{array}{l}\text { Glycyrrhiza } \\
\text { glabra }\end{array}$ & Root & Dang Forest, Gujarat \\
\hline 26 & $\begin{array}{l}\text { Terminalia } \\
\text { arjuna }\end{array}$ & Stem bark & Yeoor Hills, Maharashtra \\
\hline
\end{tabular}

\section{Preparation of Pushyanuga churna}

In-house formulation of Pushyanuga Churna was prepared as per Ayurvedic Formulary of India. Before powdering the ingredient Red ochre, also called gairika, was passed through the process of shodhana to obtain shodhita gairika. Shodhana was carried out by giving Bhavana by milk. Equal quantities (w/v) of the ingredients were boiled and ground to a soft mass after 
cooling. This process was repeated thrice and the mass was completely dried to obtain shodhita gairaka. Further, all the ingredients were mixed thoroughly in specified ratio (1 part each) to obtain a homogeneous blend of powders.

\section{Marketed samples}

Pushyanuga churna was purchased from different manufacturers like Dabur, Baidyanath, Arkashala, Dhootpapeshwar, Patanjali, and also from a local vaidya, for fingerprint analysis and compared with the in-house formulation

\section{Quality Control evaluation \\ Physicochemical evaluation}

The churna was subjected to analysis for the estimation of solvent extractive values along with proximate parameters like ash content, acid insoluble and water soluble ash content and loss on drying using standard pharmacopeial methods.

\section{Preparation of Standard and Sample Solutions}

Stock solutions of marker compounds $(1000 \mu \mathrm{g} / \mathrm{mL})$ were prepared by dissolving $10 \mathrm{mg}$ of accurately weighed standards in small amount of methanol by making up the volume to10 $\mathrm{mL}$ in a standard volumetric flask. The stock solutions were further diluted for the preparation of working solutions. For the preparation of sample, $10 \mathrm{~mL}$ ethanol was added to accurately weighed formulation $(1.0 \mathrm{~g})$, vortexed and kept standing overnight. Next day, the extracts were filtered using Whatman filter paper no. 1 in dry stoppered test tubes and the filtrate $(10 \mu \mathrm{L})$ was used for HPTLC analysis.

\section{HPTLC - Instrumentation and operating conditions}

Chromatographic separation was achieved on silica gel ${ }^{60}$ F254 precoated HPTLC plates. Samples were spotted using the CAMAG Linomat 5 sample spotter (CAMAG Muttenz, Switzerland) equipped with syringe (Hamilton, 100 $\mu \mathrm{L}$ ). For the development of fingerprints, plates were developed in a glass twin trough chamber (CAMAG) pre-saturated for 20 mins with toluene: methanol: formic acid (8:1:0.3, v/v) mobile phase. The plates were derivatized in $10 \%$ methanolic sulphuric acid, $1 \%$ anisaldehyde and Liebermann Buchard reagent individually. For the simultaneous estimation of the biomarkers, ursolic acid, $\beta$ sitosterol and lupeol, a simple toluene: methanol mobile phase (8: $1, \mathrm{v} / \mathrm{v}$ ) was developed and validated as per ICH guidelines. $10 \%$ Methanolic sulphuric acid reagent was used for derivatization. Densitometric scanning was performed using CAMAG TLC Scanner 4 at 366nm and CAMAG Reprostar 3 was used for photodocumentation. Fingerprint plate was also photo-documented at multiple wavelengths before derivatization and after derivatization inorder to visualize the maximum number of phytoconstituents.

\section{Method Validation}

The developed HPTLC method for the estimation of ursolic acid, $\beta$-sitosterol and lupeol was validated as per ICH guidelines.

\section{Specificity and sensitivity}

Specificity of the method was confirmed by comparing the marker bands present in the sample with that of the respective reference standards in terms of its $\mathrm{R}_{\mathrm{f}}$ value and color. Sensitivity of the method was determined with respect to limit of detection (LOD, S/N ratio of 3:1) and limit of quantification (LOQ, S/N ratio of 10:1).

\section{Preparation of calibration curve and quality control samples}

For constructing the calibration curve, appropriate dilutions were prepared from the stock solutions. The working standards in the range of $5-150 \mu \mathrm{g} \mathrm{mL}^{-1}, 15-35 \mu \mathrm{g} \mathrm{mL}^{-1}, 45-105 \mu \mathrm{g}$ $\mathrm{mL}^{-1}$ for ursolic acid, $\beta$-sitosterol and lupeol, respectively, were used to obtain a seven point linear calibration curve. Further, quality control samples (LQC, MQC and HQC) were prepared and analyzed for precision, accuracy and ruggedness studies.

\section{Repeatability and precision}

The repeatability of the method was affirmed by analyzing $5 \mu \mathrm{g} / \mathrm{mL}$ samples of all the three markers on a HPTLC plate $(n=5)$ and precision were assessed by measurement of intra and inter-day variation in the area of the markers. The result was expressed as \% RSD.

\section{Accuracy and ruggedness}

The accuracy of the method was assessed by spiking the QC samples in the formulation and calculating the percent recovery for each marker. Ruggedness was assessed by deliberately incorporating small variations in the optimized chromatographic conditions. Response and Rf were observed. Results were expressed in terms of percent mean deviation.

Assay

The content of all the three markers from the in-house formulation was determined by applying the samples $(10 \mu \mathrm{L})$ along with pure standards.

\section{Estimation of the markers}

The quantity of the markers was calculated using the regression equation obtained from the regression analysis of the calibration curve.

\section{Statistical Analysis}

The statistical analysis of the results obtained was done using Microsoft Excel 2007.

\section{RESULT AND DISCUSSION}

Quality assurance is an integral part of medicine which in-turn ensures quality medication. Thus, there is a urgent need for the evaluation of such parameters which can be adopted by pharmaceutical industries (Shailajan et al., 2011a). There are similar reports on the standardization of some popular Ayurvedic medicines (Shailajan et al., 2011b; Rashmibala and Kumar, 2011; Shailajan et al., 2010; Parameshwaran and Nandan; 2010) 
Table 1: Proximate analysis the inhouse formulations.

\begin{tabular}{ccc}
\hline Parameters & Results $(\mathbf{N}=3)$ & Limits -NMT\%* \\
\hline Total ash & $12.57 \pm 0.25$ & NMT 15\% \\
Acid insoluble & $1.26 \pm 1.32$ & NMT $4 \%$ \\
Water soluble & $9.42 \pm 1.68$ & NMT 13\% \\
Loss on drying & $5.75 \pm 0.92$ & NMT $11 \%$ \\
\hline
\end{tabular}

* NMT: Not More Than; Limits have been suggested.

Table 2: Detection of Preliminary Phytoconstituents.

\begin{tabular}{ccc}
\hline Phytoconstituents & Aqueous extract & Ethanolic extract \\
\hline Flavonoid & Present & Present \\
Tannin & Present & Present \\
Alkaloid & Present & Present \\
Glycosides & Absent & Absent \\
Oil & Absent & Absent \\
Resin & Present & Present \\
\hline
\end{tabular}

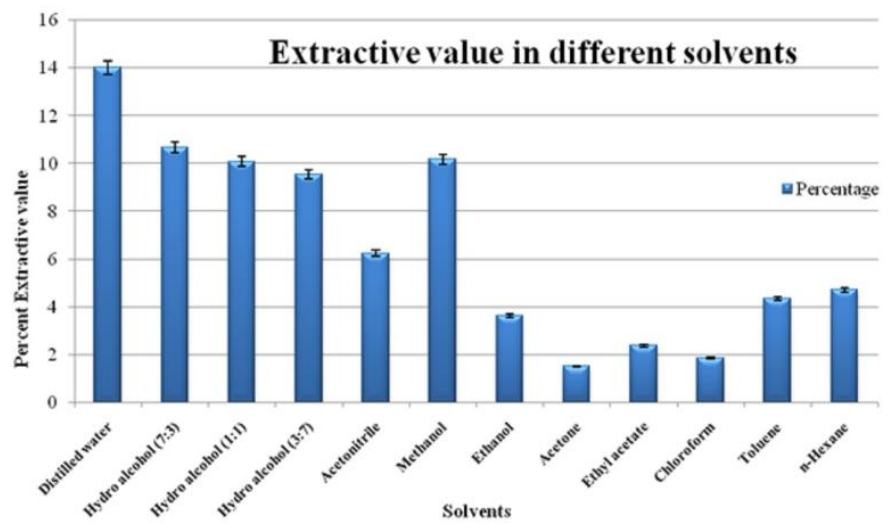

Fig. 1: Extractive values of Pushyanuga Churna in solvents of varying polarities.

\section{Physicochemical analysis}

The results for proximate parameters, preliminary phytochemical analysis and extractive values in various solvents have been summarized in the Tables 1, 2 and Figure 1 respectively. The results obtained for total ash, acid insoluble and water soluble ash, along with loss on drying were found to be within the permissible limits for the formulation as prescribed by the Ayurvedic formulary of India. Among the phytoconstituents analysed, glycosides and oil was found to be absent whereas flavonoids, tannins, alkaloids and resins were found to be present (Table 2). Percent extractive value was found to be highest in distilled water, followed by hydro-alcohol (7:3) in the category of organic solvents. Hence it can be concluded that, Pushyanuga churna contains more polar components. But comparatively better values were also observed in non -polar solvents like n-hexane suggesting good quantities of non-polar components too (Fig. 1).

\section{Method development}

Ursolic acid, $\beta$-sitosterol, lupeol are phytomarkers which have been reported for numerous therapeutic activities including in the treatment of female reproductive disorders but the presence of these markers has not yet been established from Pushyanuga churna.

Hence, in the current research work, these markers have been quantitated using a simultaneous HPTLC method which can be used for the standardization of Pushyanuga churna. Optimized chromatographic conditions in order to obtain good separation amongst three triterpenoids viz. ursolic acid, $\beta$-sitosterol and lupeol are summarized in table 3 .

Table 3: Optimized chromatographic conditions for quantitation of Ursolic acid, betasitosterol and Lupeol.

\begin{tabular}{ll}
\hline \multicolumn{1}{c}{ Parameters } & \multicolumn{1}{c}{ Specifications } \\
\hline Stationary Phase & Merck silica gel 60 F254 HPTLC pre-coated plates \\
Sample Applicator & CamagLinomat 5 \\
Development distance & $85 \mathrm{~mm}$ \\
Derivatization & $10 \%$ Methanolic sulphuric acid reagent \\
Densitometric scanner & Camag scanner 4 \\
Software & winCATS planar chromatography manager \\
& software version 1.4.7 \\
Lamp, wavelength & Mercury, 366 nm \\
Photo documentation & Camag Reprostar 3 \\
\hline
\end{tabular}

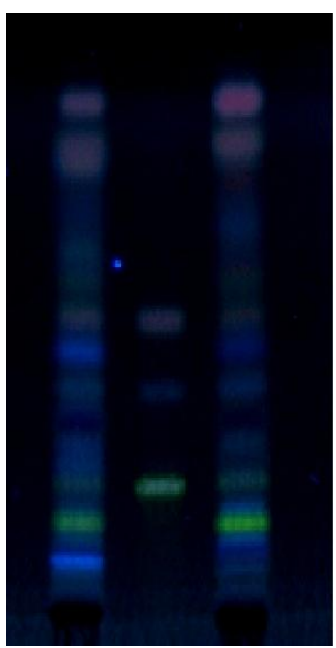

Fig. 2: Plate Photo at $366 \mathrm{~nm}$ post derivatization (Post Fig) Track details Track 1: In-house formulation Track 2: Ursolic acid, $\beta$-sitosterol, Lupeol Track 3: Marketed formulation.

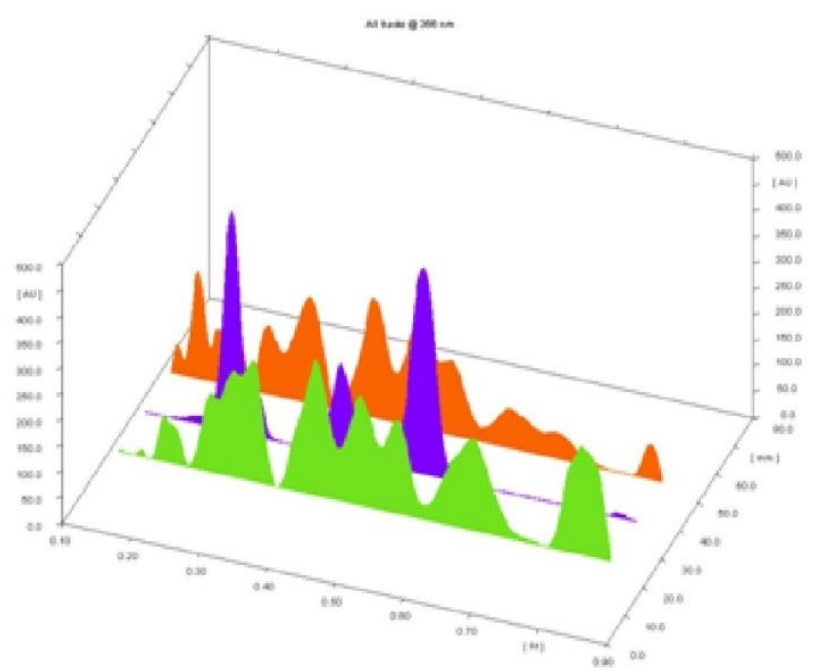

Fig. 3: 3D Overlay of plate at $366 \mathrm{~nm}$ (post Fig:) Track details: Track 1: In-house formulation Track 2: Ursolic acid, $\beta$-sitosterol, Lupeol Track 3: Marketed formulation. 
Various solvent systems were tried, out of which toluene: methanol (8:1, v/v) showed good resolution. The method developed was validated as per ICH guidelines. Visualization of spot of these markers directly under UV or visible radiation is not possible as none of them have chromophoric groups.

Therefore, developed plate was derivatized in $10 \%$ methanolic sulphuric acid reagent. The plate was air dried and kept in oven for 5-7 min at $110{ }^{\circ} \mathrm{C}$ and densitometrically scanned at 366nm (Fig. 3).

\section{Method validation}

The described method has been extensively validated in terms of specificity, linearity, repeatability, precision, accuracy, recovery and ruggedness. The results of the method validation have been summarized in table 4 . Ruggedness was assessed by deliberately incorporating small variations like change in analyst, plate batch, spotting volume and mobile phase in the optimized chromatographic conditions. The \% CV obtained during precision and ruggedness studies were found to be $<2 \%$ which suggests that the method is rugged and reproducible. With recovery values found to be above $98 \%$ in all cases, the method can be regarded as selective, accurate, precise, and robust and it has a wide scope in the area of natural product separation, characterization, drug development, and their quality control/standardization.

Table 4: Results of method validation.

\begin{tabular}{lccc}
\hline Parameters & Ursolic acid & $\boldsymbol{\beta}$-sitosterol & Lupeol \\
\hline $\mathrm{R}_{\mathrm{f}}$ & 0.31 & 0.49 & 0.60 \\
LOD and LOQ $\left(\mu \mathrm{g} \mathrm{L}^{-1}\right)$ & 1 and 5 & 5 and 15 & 15 and 45 \\
Linear Range $\left(\mu \mathrm{gL} \mathrm{m}^{-1}\right)$ & $5-150$ & $15-35$ & $45-105$ \\
System Suitability $(\% \mathrm{CV})$ & 1.8243 & 1.6344 & 1.5781 \\
Intraday Precision $(\% \mathrm{CV})$ & 1.7021 & 0.50 & 0.89 \\
Interday Precision $(\% \mathrm{CV})$ & 1.99 & 0.93 & 1.15 \\
Recovery & $98.80 \%$ & $99.32 \%$ & $98.62 \%$ \\
Regression equation & $\mathrm{Y}=$ & $\mathrm{Y}=$ & $\mathrm{Y}=$ \\
& $19.75 \mathrm{x}+48.4$ & $65.74 \mathrm{x}+91.0$ & $21.75 \mathrm{x}+211.4$ \\
\hline
\end{tabular}

\section{Detection and quantitation}

The method was further applied in the simultaneous detection and quantitation of the biomarkers from the ethanolic extract of Pushyanuga churna prepared in-house and a marketed formulation. The content of ursolic acid, $\beta$ - sitosterol and lupeol was found to be $1.37 \pm 0.108,0.73 \pm 0.025$ and $1.24 \pm 0.136 \mathrm{mg} / \mathrm{g}$ from the in-house formulation respectively. In the marketed formulation, the content was found to be $1.57 \pm 0.027,0.58 \pm$ 0.024 and $0.88 \pm 0.089 \mathrm{mg} / \mathrm{g}$ respectively (Table 5).

Table 5: Content of Ursolic acid, $\beta$-sitosterol, Lupeol in the formulation.

\begin{tabular}{lccc}
\hline & Ursolic acid & $\boldsymbol{\beta}$-sitosterol & Lupeol \\
\cline { 2 - 4 } & \multicolumn{2}{c}{ Concentration $(\mathbf{m g} / \mathbf{g})$ Mean $\pm \mathbf{S D}, \mathbf{n}=\mathbf{3}$} \\
\hline $\begin{array}{l}\text { In-house } \\
\text { formulation } \\
\text { Marketed }\end{array}$ & $1.37 \pm 0.108$ & $\mathbf{0 . 7 3} \pm \mathbf{0 . 0 2 5}$ & $\mathbf{1 . 2 4} \pm \mathbf{0 . 1 3 6}$ \\
\hline
\end{tabular}

\section{Fingerprint of Pushyanuga churna prepared in-house and compared with different manufacturers}

A chromatographic fingerprint represents the phytochemical integrity of the sample thus providing it an identity. Using these fingerprints, the authentication and identification of Ayurvedic formulations can be accurately conducted even if the concentration varies (Kulkarni et al., 2014). Hence it is very important to obtain reliable chromatographic fingerprints that represent pharmacologically active and chemically characteristic component of the herbal drug.

In the current research work a chromatographic fingerprint of an Ayurvedic formulation pushyanuga churna was established and compared to different manufacturers available in the market. Pre-derivatized plate showed less number of bands compared to post derivatization in different derivatizing reagents at different wavelength. Variations in fingerprint pattern may be due to the substitutes added to the formulation during preparation and also due to non-availability of the authentic ingredients. The variation can also be the result of variation in the quality of ingredients used and the varying collection conditions. Table 6 comprises the optimized chromatographic conditions for fingerprint.

Table 6: Optimized chromatographic conditions for fingerprint analysis of Pushyanuga Churna

\begin{tabular}{|c|c|}
\hline Parameters & Specifications \\
\hline Stationary Phase & Merck silica gel 60 F254 HPTLC pre-coated plates \\
\hline Sample Applicator & Camag Linomat 5 \\
\hline $\begin{array}{l}\text { Development } \\
\text { distance }\end{array}$ & $85 \mathrm{~mm}$ \\
\hline Derivatization & $\begin{array}{l}10 \% \text { Methanolic sulphuric acid reagent, } \\
1 \% \text { anisaldehyde, } \\
\text { Liebermann buchard reagent }\end{array}$ \\
\hline $\begin{array}{l}\text { Densitometric } \\
\text { scanner }\end{array}$ & Camag scanner 4 \\
\hline Software & $\begin{array}{l}\text { winCATS planar chromatography manager software } \\
\text { version } 1.4 .7\end{array}$ \\
\hline Lamp, wavelength & Mercury, $366 \mathrm{~nm}$ \\
\hline Photo documentation & Camag Reprostar 3 \\
\hline
\end{tabular}

Figure 4 (a, b, c, d) represent the photographic documentation of fingerprint patterns observed in various conditions. The presence of variation in bands can be traced back to the ingredients and used as a quality control tool by various manufacturing units of Pushyanuga churna. Track 1.i,e the formulation prepared in-house does show the presence of some bands which were found to be absent in many of the manufactured formulations. Among the marketed formulations, the formulation purchased from the local vaidya did show similar fingerprints. Among the manufacturer, formulation by Dhootpapeshwar followed by Baidyanath showed similarities to in-house formulation. 

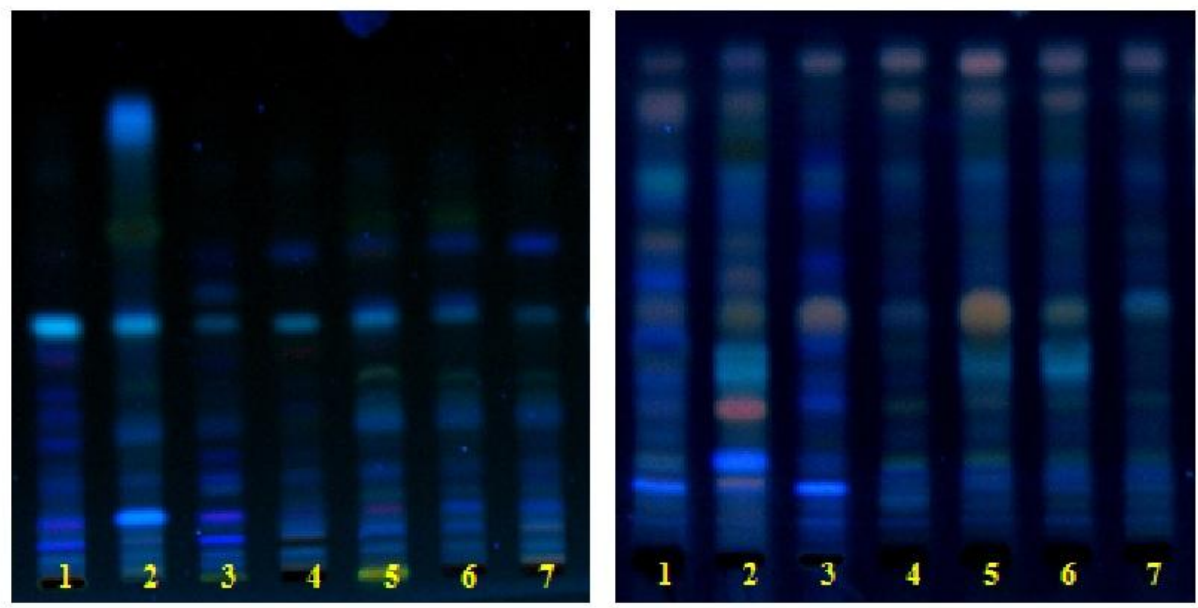

(4a)

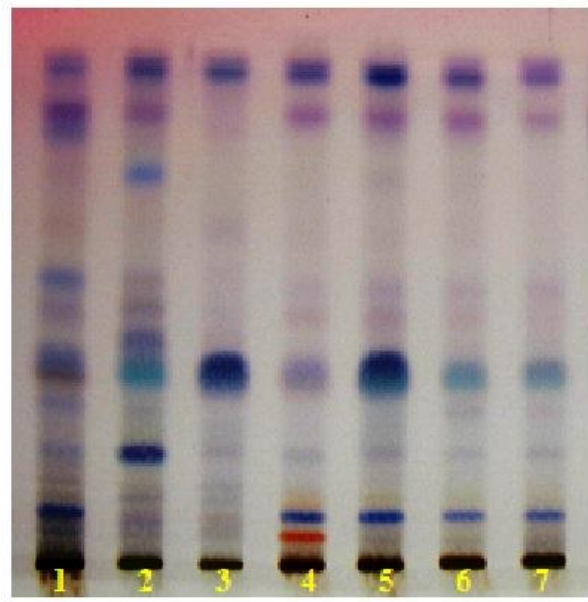

Track de tails.

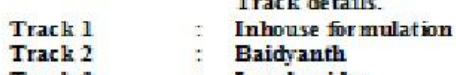

Track 3
Baidyanth

(4c) (4b)

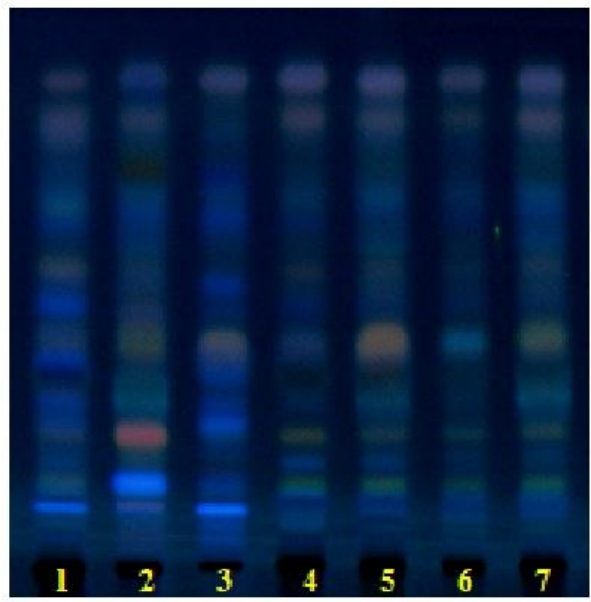

Track 4

Track 5

Track 6

Track 7
Dhootpa peshwar

Patanjali

Arkashala

Dabur

(4d)

Fig. 4: Photo of plate after derivatization with various agents (a) Pre-derivatized plate $366 \mathrm{~nm}$ (b) $10 \%$ methanolic sulphuric acid at $366 \mathrm{~nm}$ (c) $1 \%$ Anisaldehyde acid at $550 \mathrm{~nm}$ (d) Liebermann buchard reagent at $366 \mathrm{~nm}$.

\section{CONCLUSION}

Chemo profiling-assisted characterization of the polyherbal formulation Pushyanuga churna using HPTLC was generated for the first time to confirm the total number of chemical moieties which will help in identification of bioactive compounds. The markers ursolic acid, betasitosterol and lupeol quantitated in the current research are documented and reported to be associated with various therapeutic activities. The quantity of marker compounds can be used as a complementary approach for the quality control and stability assessment of Pushyanuga churna.

Any deviation from this fingerprint suggests that pharmacopoeial standards have been defaulted. Hence, the results from the current study will allow manufacturers to offer greater batch-to-batch consistency for reproducible clinical efficacy.

\section{ACKNOWLEDGEMENT}

We would like to thank Mayuresh Joshi, Deepti Gurjar, Dipti Singh, Suhina Bhosale, Swati Singh, and Reena Mascarenhas for their help in the field work.

Financial support and sponsorship: Nil.

Conflict of Interests: There are no conflicts of interest.

\section{REFERENCES}

Devi KP. Clinical evaluation of Pushyanuga churna and Lodhrasava in Rakta pradara. Indian Journal of Traditional knowledge. 2007; 6(3), 429-431.

Gong F, Wang BT, Chau FT, Liang YZ. 2005. Data preprocessing for chromatographic fingerprint of herbal medicine with chemometric approaches. Analytical Letters. 2005; 38:2475-2492. 
Jyotshna, Singh IP. Pharmaceutical standardization of Indigenous traditional medicine: Dhatri lauh. International journal of drug development and research. 2013; 5(3):454-460.

Kamboj A. Analytical Evaluation of Herbal Drugs, Drug Discovery Research in Pharmacognosy. 2012; 23-60.

Khare CP, Katiyar CK. 2012. The Modern Ayurveda : Milestones beyond the Classical Age, CRC press, New-york.

Khot BM, Lad MD, Patil AJ, Kakad AC. Clinical efficacy of Ayurveda treatment on polycystic ovarian syndrome. Journal of Pharmacy, 2013; 3(4):21-25.

Kulkarni KM, Patil LS, Khanvilkar VV, Kadam VJ. Fingerprinting techniques in herbal standardization. Indo American Journal of Pharmceutical research, 2014; 4(02): 1049-1062.

Liang YZ, Xie P, Ch K. Quality control of herbal medicines. Journal of chromatography B. 2004; 812:53-70.

Parmeshwaran S, Nandan DM. Standardization of an Ayurvedic formulation Sanjeevani vati. International Journal of Green Pharmacy. 2010; 4:153 - 155 .

Rashmibala S, Kumar SP. 2011. Standardization of Lasunadi vati: An ayurvedic polyherbal formulation. International Journal of Pharmaceutical World Research. 2011; 2:1-9.

Rastogi S, Chiappeli F, Ramchandani MH, Singh RH. Evidence-Based Practice in complementary and alternative medicine, Springer, New-york, 2012.

Reich E, Schibli A. High performance Thin-layer Chromatography for the analysis of medicinal plants. Thyme medical publishers, New York, 2006.

Shailajan S, Singh A, Tiwari B. Quality control and standardization of a Ayurvedic Taila formulation International Journal of Biomedical research analysis. 2010; 1:78 - 81 .
Shailajan S, Menon S, Yeragi M, Kelkar V. Pharmacognostic evaluation of an Ayurvedic formulation Eladi Gutika. International Journal of Green Pharmacy. 2011a; 302 - 306.

Shailajan S, Yeragi M, Purohit A. Optimization separation nd quantification of eugenol from a traditional unani medicine Jawarish $-e$ Bisbasa using HPTLC. International Journal of Pharmaceutical Sciences Review and research. 2011b; 9:146 - 151 .

Sharan PG. Glimpse of Astrology in Ayurveda. International Ayurvedic medical Journal, 2016; 4(8):2320-5091.

Singh N, Kuma S. TLC and HPTLC fingerprint development of Aegle marmelos Corr. And its polyherbal marketed formulations. International Journal of Pharma Sciences and Research. 2015; 6(1):162167.

The Ayurvedic Formulary of India (AFI), Part-I, Second ed., Controller of Publications Civil Lines, New Delhi, 113. 2003.

The Ayurvedic Pharmacopoeia of India (API), Part-II (Formulations), Vol-I, First ed. Controller of Publications Civil Lines, New Delhi, 55-56. 2008.

World Health Organization (WHO). General Guidelines for Methodologies on Research and Evaluation of Traditional Medicines. 2001 .

\section{How to cite this article:}

Shailajan S, Patil Y, Menon S. Marker based Chemo profiling of a traditional formulation: Pushyanuga Churna. J App Pharm Sci, 2017; 7 (08): 239-245. 